\title{
The Management to Strengthen the Coal Mine Safety in China Based on Cooperative Game Theory
}

\author{
Xiaojie Zhai \\ School of Mining and Safety Engineering, Shandong University of Science and Technology, Qingdao \\ 266590, China. \\ zhxj0603@sina.com
}

Keywords: safety economics, cooperative game, coal enterprise, security interest.

\begin{abstract}
According to the current situation of China's coal mine production safety management such as lack of sense of responsibility, lack of safe input and other phenomena. With the help of cooperative game model, this article establishs game model of coal Supervision Bureau as the representative of the government departments, the coal mining enterprises, and miners. By this modle drawing a conclusion to solve the distribution of security interests that all three parties could accept. Based on the cooperative game model, the paper puts forward some measures to strengthen the safety management of coal industry in China. The government plays a regulatory function. The enterprises actively increase the safety input, at the same time, the enterprises give employees the rights of the safety production supervision. And employees strengthen the awareness of legal rights and conscious operation. Through the three parties cooperation to increase safety investment, it is conducive to reducing security incidents, as well as the steady development of coal industry safety management.
\end{abstract}

\section{Introduction}

In recent years, accidents in coal mines had occurred frequently. What's more, the status of the coal production industry is not satisfactory. Government officials often operate illegally and hidden dangers with these who harbor the coal mine enterprises. As for enterprise, they not only considered the immediate benefits but also ignored the production management and the corresponding skills training. The above mentioned have a bad influence to the formation of a large security environment throughout the industry. The safety status of coal industry needs urgent renovation, and it depends on the efforts of government, enterprises and employees. Only in this way, can social security benefit from achieves sustained growth. The three parties can achieve win-win cooperation in the game, which conforms to the basic principles of the cooperative game theory. Therefore, relying on the cooperative game model, we can study the way and method of the coal mine enterprise safety management mode in depth.

\section{Cooperation Game Between the Three Parties of Government, Enterprise and Employee}

In the past researchs, most of the problems have analyzed the zero-sum game between the enterprise and the government, which means that there is a fierce competition between them. But in the really production management, the government supervision department, the enterprise and the staff all exist together and restrict with each other. Through the cooperative game, not only can the parties find the basis of cooperation in the confrontation, but also makes social benefits increase.

\subsection{The Composition of the Cooperative Game Model.}

The three parties of the game are, government safety supervision departments, which refers to the national and local safety supervision and management of the General Administration (herein after referred to as the safety supervision bureau), coal enterprises and miners. Remember the three set as $\mathrm{N}=\{1,2,3\}$. If any of the arbitrary subset s(representing any combination of any two of the three) of $\mathrm{N}$ corresponds to a real value function $\mathrm{V}(\mathrm{s})$. And it satisfies the expression that $\mathrm{V}(\phi)=0$ and $\mathrm{V}\left(\mathrm{s}_{\mathrm{i}} \cup \mathrm{s}_{\mathrm{j}}\right) \geq$ $\mathrm{V}\left(\mathrm{s}_{\mathrm{i}}+\mathrm{s}_{\mathrm{j}}\right)$ which the premise is $\mathrm{V}\left(\mathrm{s}_{\mathrm{i}} \cap \mathrm{s}_{\mathrm{j}}\right)=\phi$. If the above conditions can be met, we can call $[\mathrm{N}, \mathrm{V}]$ as three cooperation countermeasures. Among them, $\mathrm{V}$ is called the characteristic function of the game and $\mathrm{V}(\mathrm{s})$ 
is called the safety benefit of coal mine safety management cooperation alliance s. The Shapley value which marked $\mathrm{X}=\left(\mathrm{X}_{1}, \mathrm{X}_{2}, \mathrm{X}_{3}\right)$ is determined by the characteristic function $\mathrm{V}$. And it called distribution strategy of coal mine safety management. And to any $\mathrm{i}$ that from one to three, $\mathrm{X}_{\mathrm{i}}$ is

$$
\begin{aligned}
& X_{i}(V)=\sum_{S_{i} \in S} W(|s|)[V(s)-V(s-i)] \\
& W(|s|)=\frac{(3-|s|) !(|s|-1) !}{3 !}
\end{aligned}
$$

Where: s-contains all subsets of coal mines, enterprises, government, and employees;

$|\mathrm{s}|$-the number of combinations in subset $\mathrm{s}$;

$\mathrm{W}(|\mathrm{s}|)$-weighting factor;

$\mathrm{V}(\mathrm{s})$-the cooperative security gains of combination $\mathrm{s}$ which included $\mathrm{i}$ in the three parties;

$\mathrm{V}(\mathrm{s}-\mathrm{i})$-portfolio income not included $\mathrm{i}$.

\subsection{Cooperative Game Model Solution.}

The above model has innumerable effective solutions, and the key is to get the rational interpretation model which can mate the interest of all parties. We use the inverse solution, and set the degree of dissatisfaction of the union as $\mathrm{m}$. When $\mathrm{m}$ is the smallest, the number of $\mathrm{X}_{1}, \mathrm{X}_{2}, \mathrm{X}_{3}$ is the optimal solution.

In the actual production process, the contribution of the three coalitions to the safety benefits is different. Enterprises are engaged in production activities such as equipment and materials, however, the government created relatively small social benefits. Therefore, the alliance between companies and employees in all the alliances will produce the greatest security benefits. We can set up a business and staff alliance contribution ratio of up to $5 / 6$, that means $\mathrm{V}(2,3)=5 / 6$, government and business alliance contribution ratio of $1 / 3$; and government and staff alliance contribution ratio is only $1 / 6$.

There are many ways for coal mining enterprises, governments and employees to work together. First, we find V(s) of several combinations, and then find V(s-i) in the case of cooperation without participation of i. Finally, according to the cooperative game distribution strategy given by Shapley, the cooperative income of coal mining enterprises, government and employees in coal mine safety management cooperation is calculated as $X_{1}=1 / 12, X_{2}=7 / 12, X_{3}=4 / 12$. Then the dissatisfaction of the alliance scheme formed by "1", "2" and "3" is calculated separately, and the minimum value of $\mathrm{m}$ is obtained according to the system.

\section{Strengthen the Safety Production Management Strategy Based on Cooperative Game Model}

For the three aspects of the cooperative game, which are the government, enterprises, and employees. In fact, the relationship between them checks and balances by the interests of each other and it must be mutual supervision and mutual cooperation. Any party's own body which pursues their own interests to maximize, will lead to the collapse of the Union and the failure of cooperation game.

\subsection{The Government Performs Regulatory Functions.}

In the actual production process, the government hold the view that companies will not consciously carry out security investment, so a separate analysis of government and business alliance is non-cooperative game. As a result, the government's security supervision function is particularly important.

(1)The coal office should use the functions of macro-control to effectively supervise coal enterprises to prevent accidents in coal production, which is showed in Fig. 1. Only by correctly exercising the right of the government properly can we guarantee the development of the great security environment of the coal industry and the stable development of the economy. 


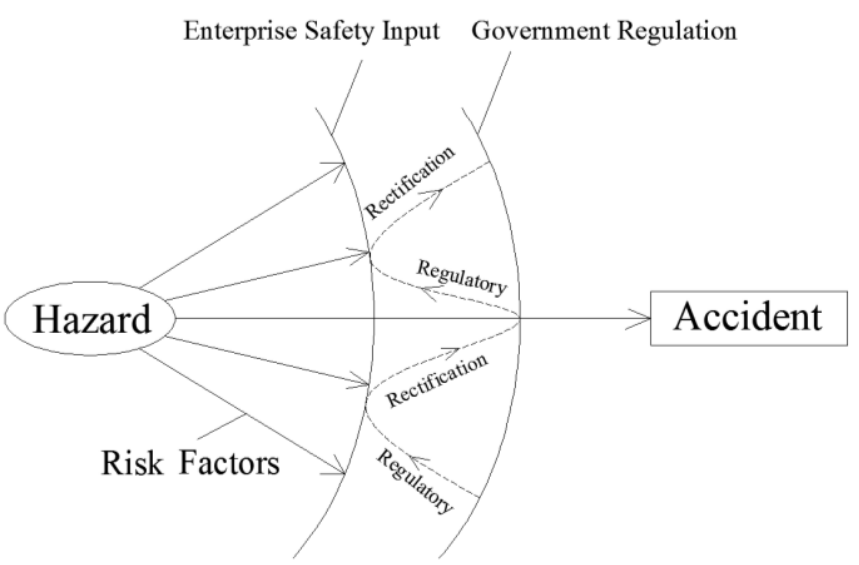

Fig. 1 Effect diagram of government supervision function

The government's supervision directly creates a favorable environment for the safe production of the enterprise, and puts an end to the development of the safety factor accounting for safety accident, which indirectly improves the overall economic efficiency, and avoids the negative social impact caused by the accident. At the same time, as a hidden security benefits, the government's supervision avoids the social impact of accidents.

(2)If we want to achieve the goal which is government regulation may not be destroyed, we should rely on long-term improvement in the coal industry. For those common phenomenon that the poor self awareness of coal mining enterprises, we should increase the government's law enforcement efforts. Only in this way, can we effectively promote enterprises, increase the security investment and establish a complete safety production system. The security bureau can increase the punishment of substandard enterprises and then can avoid the safety risks of coal enterprises. The greater the scale and number of investments of an enterprise, leading a greater scale of production and the better safety supervision must be set up.

\subsection{Enterprise Achieve Stable Development by Pressing the Security.}

As the core element of the whole game board, the companies make the largest contribution to the benefit of security, and directly connect with the government and the employees. There are a lot of mine companies have poor safety consciousness and conscientiousness. So only by paying attention to enterprise security, could we achieve the steady development of the future of the company.

(1) Responsibility for employees

The improvement of enterprise security level can't be separated from the participation of employees. If we want to avoid the occurrence of unsafe behaviors, we should strictly supervise the workers' behavior. Employees look highly of personal benefits, the miners' unsafe operation can be connected with the rewards and punishments. During this way, the company can motivate employers to obey the rules consciously.

(2) Responsibility for ourselves

Through the analysis of the cooperation and confrontation between SACMS, coal mining enterprises and miners, we can see that the proportion of the relative security interest of any coal mining enterprise in the game bureau is invariable. Only by three of them working together, they can all get more absolute security gains. If companies eager to get the maximization of their own interests, and ignored the government's supervision and oversight of the staff, the balance between the three will disappear, which means the whole game will collapse. From a long-term point of view, mine enterprises must carry out reasonable safety investment whatever the absolute security interests of enterprises and the safety production should be put into the enterprise safety culture, which in order to achieve long-term security interests of enterprises. 


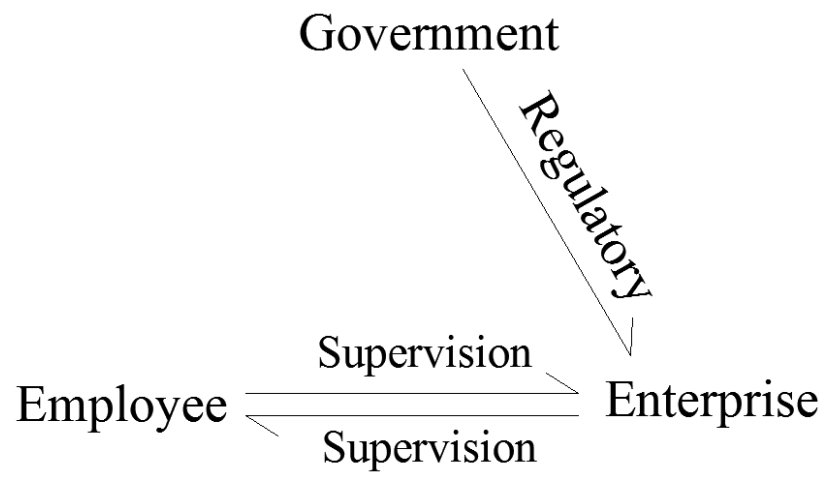

\subsection{Employee.}

Fig. 2 The Relationship Between Government, Enterprises and Employees

Employee is one of the most important parts of the enterprise, who is the implementation of the production and the direct victims of the accident. The safety level of enterprises can't be separated from the participation of employees.

(1) Miners should participate in pre-job training and related safety before they start working, and the training can strengthen their own knowledge. In addition, they should consciously abide the safety rules and regulations, timely reporting of security risks, urge enterprises to rectify and so on, which can ensure the safety of their life.

(2) Employees are inferior to the enterprise, so they have to cultivate their own legal thinking and learn to use legal as their weapon to obtain their legitimate right and interests. At the same time, government should strengthen the role of trade unions, which to ensure that the legitimate interests of employees in the game are not violated.

\section{Conclusion}

Based on the analysis of the cooperation model, which is composed of the coal Supervision Bureau which is represented the government departments, the coal mining enterprises and the miners, the three restrict each other and complement each other. According to the formula given by Shapley cooperation game allocation strategy, security interests allocation solution of coal mine safety management cooperation model, we can enterprise to obtain the most visible security interests. So in the coal mine safety management activities, we should pay attention to the safety behavior of coal mine enterprises.

If we want to improve the current production situation of the coal industry, government departments should govern according to law and strictly play the regulatory functions; Coal mine enterprises should actively improve enterprise safety culture, increase safety investment, monitor the coal miners' compliance in the actual production, while giving employees the right to safety supervision; As a direct victim of the accident, employees in the course of the work should be enhanced safety awareness, and by means of law to safeguard their rights and interests. The coordinated development of government, enterprises and employees can make their own security benefits continue to grow, which is conducive to the formation of the coal industry environment. So that it brings considerable security benefits for the community.

\section{References}

[1] Zhu Hua-li, Xu Feng. Economic analysis of insufficient investment in coal mine safety in China [J]. Journal of coal mine safety ,2010,424:108-111.

[2] Wang Ying, Zhang Li-quan, Li Qian. The cooperative game theory in common governance change reform of state-owned coal enterprises[J]. Journal of coal industry,2009,34(6):861-864.

[3] Lu Hai-xu. Game analysis of coal mine safety supervision[J]. Journal of xi 'an university of posts and telecommunications, 2009,14:143-150.

[4] Chen Ben-yang. Analysis of the game and behavioral economics behind frequent mining accidents[D]. Anhui:Anhui University Of Science And Technology,2011. 
[5] Jiang Peng-fei. Cooperative game solution and its application research[D]. Shandong:Shandong University,2007.

[6] Kong Xiang-rong, Han Bo-tang. Transportation allocation method based on cooperative game theory[J]. Journal of System engineering theory and practice,2010,30(4):1340-1344.

[7] Xu Yan, Chen Xin. Method of transformer state assessment based on cooperative game and cloud model [J]. Journal of power automation equipment,2015,35(3):88-93.

[8] Xue Jian, Xie Wan-lin, Li Chang-min. Inter-provincial cooperative game model of BeijingTianjin-Hebei air pollution control[J]. Journal of System engineering theory and practice, 2014, 34(3):810-816. 